\title{
Hepatoprotective and antioxidant activity of Bombax ceiba flowers against carbon tetrachloride-induced hepatotoxicity in rats
}

\author{
Manish M. Wanjari ${ }^{1}$, Rachna Gangoria ${ }^{2}$, Yadu Nandan Dey ${ }^{1}$, Sudesh N. Gaidhani ${ }^{3}$, \\ Narendra K. Pandey ${ }^{1}$, Ankush D. Jadhav ${ }^{1}$
}

${ }^{1}$ National Research Institute for Ayurveda-Siddha Human Resource Development, Gwalior 474009, Madhya Pradesh, India. ${ }^{2}$ School of Studies in Biochemistry, Jiwaji University, Gwalior 474011, Madhya Pradesh, India.

${ }^{3}$ Central Council for Research in Ayurvedic Sciences, New Delhi 110058, India.

\begin{abstract}
Aim: The flowers of Bombax ceiba are traditionally used as home remedy in the treatment of jaundice and spleen enlargement. The present work investigated the effect of aqueous extract of flowers of Bombax ceiba (BCAE) on experimentally induced hepatotoxicity in rats to substantiate its traditional use as hepatoprotective agent. Methods: Hepatotoxicity was induced in rats by carbon tetrachloride $\left(\mathrm{CCl}_{4}\right)$ treatment; at the same time vehicle or BCAE (250 or $500 \mathrm{mg} / \mathrm{kg}$ ) or silymarin $(25$ $\mathrm{mg} / \mathrm{kg}$ ) were administered daily orally for seven days. Hepatotoxicity was assessed by estimating the activities of marker enzymes and by histological studies. The antioxidant effect of BCAE was assessed by measuring amount of antioxidant phytochemicals (total phenolics and flavonoids), and DPPH free radical scavenging assay of the extract. Results: BCAE treatment significantly prevented the $\mathrm{CCl}_{4}$-induced elevations in levels of glutamate oxaloacatate transaminase, glutamic pyruvic transaminase, alkaline phosphatase, bilirubin, and triglycerides, and decreased the total protein levels. Treatment with $\mathrm{BCAE}$ attenuated the $\mathrm{CCl}_{4}$-induced cytotoxic damage to liver. BCAE exhibited presence of antioxidant phytochemicals and showed scavanging action on DPPH radicals. The hepatoprotective effect of BCAE was comparable to that of the standard antioxidant hepatoprotective agent, silymarin. These findings indicated that BCAE showed hepatoprotective effect against $\mathrm{CCl}_{4}$-induced hepatotoxicity and exhibited in vitro antioxidant effects. Conclusion: Bombax ceiba flowers exhibited hepatoprotective effect which may be attributed to antioxidant potential. This study also validated their traditional medicinal use in liver disorders.
\end{abstract}

Key words: Semal; liver disorders; liver function test; free radical scavenging; silymarin

\section{Address for correspondence:}

Dr. Manish M. Wanjari, National Research Institute for Ayurveda-Siddha Human Resource Development, Gwalior 474009, Madhya Pradesh, India. E-mail: manish.nriashrd@gmail.com

Received: 09-09-2015, Accepted: 30-11-2015

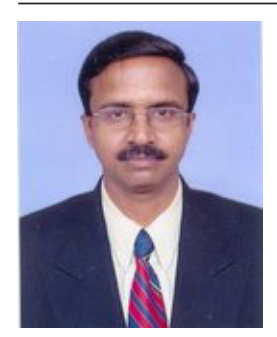

Manish M. Wanjari, PhD, is a pharmacology scientist involved in research on medicinal plants and Ayurvedic formulations since last 10 years. His major research area is herbal drug development for diabetes, inflammation, etc. He published 30 research papers in national and international journals. He is life member of various scientific societies.

\begin{tabular}{|l|c|}
\hline \multicolumn{2}{|c|}{ Access this article online } \\
\hline \multirow{2}{*}{ Website: } & Quick Response Code \\
http://www.hrjournal.net/ & \\
\hline &
\end{tabular}

This is an open access article distributed under the terms of the Creative Commons Attribution-NonCommercial-ShareAlike 3.0 License, which allows others to remix, tweak, and build upon the work non-commercially, as long as the author is credited and the new creations are licensed under the identical terms.

For reprints contact: service@oaepublish.com

How to cite this article: Wanjari MM, Gangoria R, Dey YN, Gaidhani SN, Pandey NK, Jadhav AD. Hepatoprotective and antioxidant activity of Bombax ceiba flowers against carbon tetrachloride-induced hepatotoxicity in rats. Hepatoma Res 2016;2:144-50. 


\section{INTRODUCTION}

The liver is exposed to many kinds of xenobiotics and therapeutic agents and has large capacity for metabolic conversions. As the liver is largely responsible for the biotransformation of many complex molecules, it is always at the risk of detrimental physiological and pathological alterations characterized as liver diseases. Various types of liver disorders include cirrhosis, jaundice, cancer, metabolic and degenerative lesion, liver cell necrosis, and hepatitis. ${ }^{[1]}$ Steroids, vaccines and anti-viral drugs, which have been employed as a therapy for liver diseases, have potential adverse side effects especially when administered for long term. ${ }^{[2]}$ Hepatoprotective agents of plant origin have attracted special interest, and numerous medicinal plants and their formulations have been used for liver disorders in the Ayurvedic system of medicine. These medicinal plants have been studied for their influence on liver dysfunction. ${ }^{[3]}$

Bombax ceiba Linn. (Family: Bombacaceae), is a large, deciduous tree commonly known as Silk Cotton Tree, Indian Red Kapok tree, Semal, Shimul and Shalmali. It is found throughout India and other parts of tropical and sub-tropical Asia, Australia, and Africa. The plant has both economic and medicinal value. It yields gum and cotton. It is a large and long-living tree species which gives strength to the body, mind, and heart. ${ }^{[4]}$ The plant is popular among the tribal communities for the treatment of various diseases. Almost every part of the plant, the seeds, flowers, roots, and barks of Bombax ceiba have a long history of medicinal uses. The paste of flowers and leaves are applied externally to relieve swellings, boils, and various skin conditions. The traditional healers of Chhattisgarh Plains boiled the flowers throughout the night, and gave them with mustard seeds orally as treatment of enlarged spleen..$^{[5]}$ The decoction of the semal flowers is used as home remedy for the treatment of jaundice. The flowers, leaves, and stem of Bombax ceiba have been evaluated for various pharmacological actions. The various extract of Bombax ceiba have shown analgesic, oxytocic $^{[6]}$ hypotensive, hypoglycemic, ${ }^{[7]}$ antimicrobial, ${ }^{[8,9]}$ antioxidant, ${ }^{[10-12]}$ antiangiogenic ${ }^{13]}$ activities.

Despite the traditional use of this plant in the treatment of jaundice and splenic enlargement, very few scientific studies have been carried out to delineate its influence on experimentally induced hepatotoxicity. A recent study has reported hepatoprotective effect of the Bombax ceiba flowers in anti-tubercular drugs-induced toxicity. ${ }^{[14]}$ However, the effects were limited to reversal of drug-induced necrosis. Water is an extraction solvent to extract the hydrophilic antioxidants present in the plants. For use in foods, plant extracts made with water are nutritionally more relevant and would have obvious advantages in certification and safety. ${ }^{[15]}$ The present study was undertaken to validate the traditional use of Bombax ceiba in jaundice and to confirm earlier studies. Furthermore, we demonstrated the role of free radicals in hepatotoxicity, and the in vitro antioxidant activity of the flowers of Bombax ceiba.

\section{METHODS}

\section{Plant material}

The flowers of Bombax ceiba were collected from the Medicinal Garden of the National Research Institute for Ayurveda-Siddha Human Resource Development, Gwalior in April 2011. The flowers were identified by Dr. N.K. Pandey, Research Officer (Botany), National Research Institute for Ayurveda-Siddha Human Resource Development, Gwalior, Aamkho, Gwalior, India. A voucher specimen (Accession no. 410) of the authenticated Bombax ceiba flowers has been deposited in the herbarium of the Institute.

\section{Drugs and chemicals}

Carbon tetrachloride $\left(\mathrm{CCl}_{4}\right)$ was purchased from Qualigens Fine Chemicals, Mumbai, India. Olive oil (Figaro, Spain), ascorbic acid, and tannic acid were purchased from local market of Gwalior. Quercetin and DPPH (2, 2-Diphenyl1-picrylhydryl) were obtained from Sigma Chemicals, USA. Glutamic-oxaloacetic transaminase (GOT), glutamic pyruvic transaminase (GPT), and alkaline phosphatase (ALP) estimation kits (Erba-Mannheim) were procured from Transasia Biomedicals Pvt. Limited, Mumbai while total bilirubin (T) estimation kit was procured from Siemens Medical Solution Diagnostic Ltd. Baroda India. Triglycerides (TG), total protein, and albumin estimation kits were procured from Span Diagnostic Pvt. Ltd., Surat, India. All remaining chemicals used in the experiment were of the highest grade commercially available.

\section{Preparation of aqueous extract of flowers of Bombax ceiba}

The dried flowers were subjected to size reduction to a coarse powder by using dry grinder. This powder $(100 \mathrm{~g})$ was soaked in $1 \mathrm{~L}$ purified water, mixed, and kept in dark and dry place for $48 \mathrm{~h}$. Chloroform was added in quantity of $1 \%$ total mixture to prevent microbial growth. After $48 \mathrm{~h}$, the mixture was filtered initially by Muslin cloth and after that with Whatman Filter paper No.1. The filtered extract was dried using a rotary evaporator. After drying, a light brown extract was obtained $(20 \% \mathrm{w} / \mathrm{w})$.

\section{Preliminary phytochemical screening}

Preliminary phytochemical screening of aqueous extract of flowers of Bombax ceiba (BCAE) was carried out to detect the presence of various phytochemicals by standard procedures ${ }^{[16]}$ [Table 1].

\section{Animals}

Healthy adult Wistar rats of either sex weighing about 200$250 \mathrm{~g}$, between 2-3 months of age were used in the study. They were housed in groups in polypropylene cages, under standard conditions (12:12 h light:dark cycle; $22 \pm 3{ }^{\circ} \mathrm{C}$; $40-60 \%$ humidity) and had free access to standard rat pellet diet (Ashirwad brand, Chandigarh, India) and filter water, ad libitum. The experiments were carried out in accordance with 
Table 1: Phytochemical screening of the BCAE

\begin{tabular}{llll}
\hline Phytoconstituents & Phytochemical test & Inference & BCAE \\
\hline Carbohydrates & Molisch's test & Formation of violet ring at junction & + \\
Proteins & Biuret test & Appearance of violet color & - \\
& Xanthoproteic test & Formation of white precipitate \\
Amino acids & Ninhydrin test & Appearance of Purple color & Appearance of red color in chloroform layer \\
Triterpenoid sterols & Salkowski reaction & while greenish yellow in acid layer & - \\
& Solubility test & Solubility in water, ether, benzene and \\
Fats, oils and volatile oils & chloroform & - \\
& Saponification test & Formation of soap & - \\
Fats and oils & Keller Killiani test & Formation of reddish brown colour at junction & + \\
Glycosides & Shinoda test & Formation of reddish to pink color & + \\
Flavonoids & Dragendroff's test & Formation of orange colour precipitate & + \\
Alkaloids & Wagner's test & Formation of reddish brown precipitate \\
& Lead acetate test & Formation of white precipitate & + \\
Phenolic compounds & Test with $\mathrm{FeCl}_{3}$ & Appearance of bluish black color \\
and tannins & &
\end{tabular}

+: present; -: absent; BCAE: aqueous extract of Bombax ceiba

guidelines prescribed by The Committee for the Purpose of Control and Supervision of Experiments on Animals and the use of animals was approved by the Institutional Animal Ethics Committee of the Institute (Proposal No. CRI-GWL IAEC/2010/08).

\section{Acute toxicity study}

Healthy Wistar rats, starved overnight, were subjected to acute toxicity studies to determine non-observable adverse effect dose level (NOAEL) by acute toxic class method of oral toxicity as per Organization for Economic Co-operation and Development 423 guidelines. ${ }^{[17]}$ The rats $(n=3)$ were administered BCAE in the limit test dose of $2000 \mathrm{mg} / \mathrm{kg}$ and observed continuously for behavioral, neurological, and autonomic profiles for $2 \mathrm{~h}$, and after a period of $24,72 \mathrm{~h}$ and thereafter up to 14 days for any lethality, moribund state, or death. The limit test was repeated in another group of rats $(n=3)$ for confirmation and approximate $\mathrm{LD}_{50}$ determination.

\section{Experimental induction of hepatotoxicity}

Hepatotoxicity was induced in Wistar rats by intraperitoneal (i.p.) administration of $\mathrm{CCl}_{4}$ in olive oil in the ratio of 1:1 at the dose of $1 \mathrm{~mL} / \mathrm{kg}$ for two continuous days as described previously with modifications. ${ }^{[18,19]}$ After 48 h of the last dose of $\mathrm{CCl}_{4}$, blood was withdrawn from retro-orbital plexus by capillary puncture method. ${ }^{[20]}$ Plasma was separated and analyzed for the various biochemical markers of hepatotoxicity and hepatic damage.

\section{Grouping and treatments}

The rats were divided into five groups ( $n=5$ each). Group I received only olive oil ( $1 \mathrm{~mL} / \mathrm{kg}$, i.p.), and remaining groups (group II, III, IV and V) received $1 \mathrm{~mL} / \mathrm{kg}$, i.p. $\mathrm{CCl}_{4}$ in olive oil for two continuous days. While group II (control) received the vehicle of the extract ( $5 \mathrm{~mL} / \mathrm{kg}$, distilled water, orally), group III and IV received BCAE (250 and $500 \mathrm{mg} / \mathrm{kg}$ orally, respectively). Group V received silymarin suspension (25 $\mathrm{mg} / \mathrm{kg}$, orally), a known antioxidant and hepatoprotective agent. ${ }^{[21,22]}$ The vehicle/drugs were administered daily orally for seven days and $\mathrm{CCl}_{4}$ administration was done on the 5th and 6th day of vehicle/drug treatments.

\section{Assessment of liver function test and hepatic damage}

On the eigth day of the experiment, blood was withdrawn by micro-capillary technique from the retro-orbital plexus under light ether anesthesia. This technique is used with recovery in experimental circumstances and this method is also called periorbital, posterior-orbital and orbital venous plexus bleeding. Briefly, a capillary is inserted into the medial canthus of the eye (30 degree angle to the nose) with a slight thumb pressure to puncture the tissue and enter the plexus/sinus. Once the plexus is punctured, blood will come through the capillary tube which was collected in $1.5 \mathrm{~mL}$ Eppendorff tubes from the plexus. The capillary tube is then gently removed and wiped with sterile cotton. Bleeding can be stopped by applying gentle finger pressure. ${ }^{[20]}$ Blood was centrifuged at 3,000 $\mathrm{g}$ to obtain plasma, which was used to assess liver function parameters (GOT, GPT, ${ }^{[23]} \mathrm{ALP},{ }^{[24]} \mathrm{T}^{[25]}$ total protein, ${ }^{[26]}$ albumin and TG) using semi-autoanalyser (Microlab 300, Merck Specialities Pvt. Ltd. New Delhi).

\section{Histological studies}

After the withdrawal of blood, the animal was sacrificed by cervical dislocation. Abdomen was cut opened and aorta was cut to washout the blood from tissues. The liver was dissected out. A piece of liver was fixed in $10 \% \mathrm{v} / \mathrm{v}$ neutral buffered formalin. Serial sections (4-5 $\mu \mathrm{m}$ thick) of the paraffin-embedded tissue blocks were cut with a Microm HM 360 microtome and processed for hematoxylin and eosin (HE), Masson's trichrome (Accustain Trichrome Stains, SigmaAldrich Inc, USA). Staining was done as per manufacturer's protocol. The sections were studied under microscope.

\section{Assessment of antioxidant activity}

Quantitative estimation of antioxidant phytochemicals

The total phenolic content of the extracts was determined spectrometrically ${ }^{[27]}$ and expressed as milligrams of tannic acid equivalents (TAE) per gram of extract. Total flavonoid content was measured by aluminum chloride colorimetric assay ${ }^{[28]}$ and expressed as milligrams of quercetin equivalent per gram of extract. 
DPPH (1, 1-Diphenyl-2-picryl-hydrazil) free radical scavenging activity

The free radical scavenging activity of extract was measured by 1, 1-diphenyl-2-picryl-hydrazil (DPPH •) using the method previously described. ${ }^{[29]}$ Briefly, $0.1 \mathrm{mmol} / \mathrm{L}$ solution of DPPH in ethanol was prepared, and $3.5 \mathrm{~mL}$ was added to $0.5 \mathrm{~mL}$ of extract solution of different concentrations in water. The mixture was shaken vigorously and allowed to stand at room temperature for $30 \mathrm{~min}$. Then the absorbance was measured at $517 \mathrm{~nm}$ by using a spectrophotometer (UV 1800, Shimadzu Corporation, Japan). Lower absorbance of the reaction mixture indicated higher free radical scavenging activity. Ascorbic acid was taken as standard antioxidant. The percent DPPH scavenging effect was calculated using the following equation: DPPH • scavenging effect $(\%)=100 \times \mathrm{A}_{1} / \mathrm{A}_{0}$ (where $A_{0}$ was the absorbance of the control reaction and $A_{1}$ was the absorbance in the presence of the test).

\section{Statistical analysis}

The data were analyzed by one-way ANOVA followed by Tukey's multiple comparisons post hoc test. A statistical difference of $P<0.05$ was considered significant in all cases.

\section{RESULTS}

\section{Phytochemical screening of BCAE}

The qualitative tests for identifying the nature of phytochemicals in BCAE revealed the presence of flavonoids, carbohydrates, sterols, glycosides, alkaloids, volatile oils, and phenolic compound. However, proteins were found to be absent in the extract [Table 1].

\section{Acute toxicity study of BCAE}

Acute oral toxicity studies revealed that the BCAE was safe up to a dose level of $2,000 \mathrm{mg} / \mathrm{kg}$ of body weight (limit test) and NOAEL dose is more than $2,000 \mathrm{mg} / \mathrm{kg}$. No lethality or any toxic reactions or moribund state were observed up to the end of the observation period of 14 days.

\section{Effect of $\mathrm{CCl}_{4}$ treatment on liver function test}

One-way ANOVA showed that the $\mathrm{CCl}_{4}$ treatment $(1 \mathrm{~mL} / \mathrm{kg}$, i.p. on continuous two days) significantly influenced the liver functions parameters $(P<0.0001$ in all cases). Post hoc

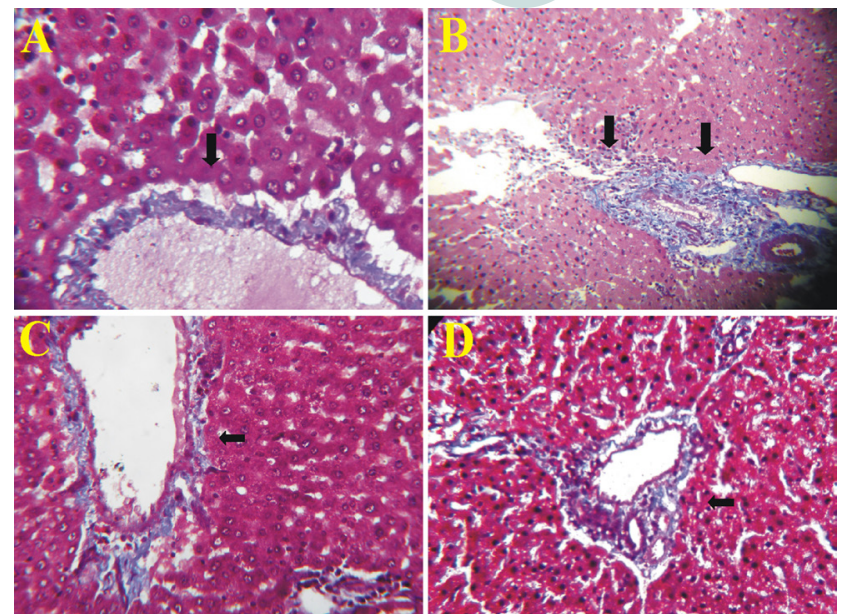

Figure 1: Effect of aqueous extract of Bombax ceiba on histopathology of liver. Histological sections of liver stained with Masson's trichrome stain from olive oil treated control rats $(A)$ shows normal hepatic architecture with central canal having radiating hepatocytes. Minimal amount of collagen tissue (arrow) stained blue with Masson's stain in the portal triad. Liver section from $\mathrm{CCl}_{4}$ treated rats $(B)$ that received vehicle showed hepatocellular degeneration with moderate amount of collagen tissue (arrow) stained blue with Masson's stain in the portal triad. Section of liver of $\mathrm{CCl}_{4}$ treated rat which concurrently received silymarin (C) and the aqueous extract of flowers of Bombax ceiba $(500 \mathrm{mg} /$ $\mathrm{kg}$ ) (D) respectively, shows lesser amount of collagen and was comparable to control (A), showing minimal amount of collagen tissue (arrow) stained blue with Masson's stain in the portal triad.

test indicated $\mathrm{CCl}_{4}$ treatment significantly $(P<0.001$ in all cases) elevated plasma levels of GOT, GPT, ALP, and T while decreased the albumin and total protein and TG as compared to olive oil control [Table 2].

\section{Effect of BCAE treatment on liver function test}

One-way ANOVA showed that BCAE ( 250 or $500 \mathrm{mg} / \mathrm{kg}$ per day, orally) or silymarin ( $25 \mathrm{mg} / \mathrm{kg}$ per day, orally) treatment for seven days significantly influenced the liver functions parameters $(P<$ $0.0001)$ in $\mathrm{CCl}_{4}$ treated rats. The BCAE or silymarin significantly $(P<0.05-0.001)$ attenuated the elevation in levels of GOT, GPT, ALP, T, and TG while increased total protein without affecting the levels of albumin [Table 2]. The effect of BCAE was lesser than that of standard drug silymarin.

\section{Effect of BCAE treatment on histology of liver of $\mathrm{CCl}_{4}$ treated rats}

Treatment with $\mathrm{CCl}_{4}$ caused marked liver damage and fibrosis characterized by hepatocellular degeneration with moderate

Table 2: Effect of BCAE on liver function parameters

\begin{tabular}{|c|c|c|c|c|c|c|c|}
\hline \multicolumn{8}{|c|}{ Liver function parameters } \\
\hline \multirow{2}{*}{ Treatments } & GOT & GPT & ALP & Bilirubin (T) & Total protein & Albumin & TG \\
\hline & $(U / L)$ & $(U / L)$ & $(\mathrm{U} / \mathrm{L})$ & $(\mathrm{mg} / \mathrm{dL})$ & (g/dL) & $(g / d L)$ & $(\mathrm{mg} / \mathrm{dL})$ \\
\hline Olive oil & $134.0 \pm 12.69$ & $48.60 \pm 2.29$ & $137.80 \pm 10.18$ & $0.21 \pm 0.04$ & $5.10 \pm 0.30$ & $4.64 \pm 0.19$ & $156.30 \pm 17.01$ \\
\hline $\mathrm{CCl}_{4}+$ vehicle & $306.8 \pm 24.50$ * & $202.2 \pm 10.34^{*}$ & $255.20 \pm 32.87^{*}$ & $1.18 \pm 0.01^{\star}$ & $2.30 \pm 0.21^{*}$ & $4.04 \pm 0.30$ & $76.77 \pm 6.40^{*}$ \\
\hline $\mathrm{CCl}_{4}+\mathrm{BCAE} 250$ & $271.0 \pm 19.25$ & $189.0 \pm 14.39$ & $155.60 \pm 15.60 \#$ & $0.73 \pm 0.06 \#$ & $2.74 \pm 0.15$ & $3.58 \pm 0.57$ & $139.0 \pm 9.02 \#$ \\
\hline $\mathrm{CCl}_{4}+\mathrm{BCAE} 500$ & $205.8 \pm 10.01 \#$ & $153.8 \pm 16.78 \$$ & $147.6 \pm 15.42 \#$ & $0.60 \pm 0.09 @$ & $2.26 \pm 0.42$ & $3.24 \pm 0.06$ & $143.20 \pm 11.94 \#$ \\
\hline $\mathrm{CCl}_{4}^{4}+$ silymarin & 134.6×8.06@ & $58.00 \pm 5.04 @$ & 69.20土5.85@ & $0.35 \pm 0.04 @$ & $5.50 \pm 0.20 @$ & $3.27 \pm 0.30$ & $126.10 \pm 7.88 \$$ \\
\hline
\end{tabular}

Rats were treated for 7 days with vehicle or BCAE (250 and $500 \mathrm{mg} / \mathrm{kg}$, i.g.) or silymarin (25 mg/kg i.g.) along with olive oil or CCl in olive oil (1 mL/kg, i.p.) treatment on day 5 and liver functions markers (GOT, GPT, ALP, T, total protein, albumin and TG) were assessed on day 8 . Results are expressed as mean $\pm \operatorname{SEM}(n=5){ }^{*} P<0.001$ vs. olive oil or $\$ P<0.05$, $\# P<0.01$, @ $P<0.001$ vs. $\mathrm{CCl}_{4}$ treated vehicle control (one-way ANOVA followed by Tukey's multi-comparison post hoc test). GOT: glutamic-oxaloacetic transaminase; GPT: glutamic pyruvic transaminase; ALP: alkaline phosphatase; TG: triglycerides; BCAE: aqueous extract of Bombax ceiba 
Table 3: Effect of BCAE on DPPH radical scavenging

\begin{tabular}{|c|c|c|c|}
\hline & Concentration $(\mu \mathrm{g} / \mathrm{mL})$ & \% DPPH inhibition & $\mathrm{IC}_{50}$ value \\
\hline \multirow[t]{6}{*}{ BCAE } & 10 & $15.53 \pm 1.85$ & \\
\hline & 20 & $31.76 \pm 2.25$ & \\
\hline & 40 & $36.07 \pm 71.35$ & \\
\hline & 60 & $71.96 \pm 1.76$ & $50.21 \mu \mathrm{g} / \mathrm{mL}$ \\
\hline & 80 & $73.16 \pm 2.15$ & \\
\hline & 100 & $80.16 \pm 1.07$ & \\
\hline \multirow[t]{6}{*}{ Ascorbic acid } & 5 & $24.92 \pm 1.33$ & \\
\hline & 10 & $54.67 \pm 2.89$ & \\
\hline & 20 & $68.83 \pm 1.68$ & \\
\hline & 40 & $86.73 \pm 2.46$ & $3.35 \mu \mathrm{g} / \mathrm{mL}$ \\
\hline & 50 & $91.86 \pm 1.75$ & \\
\hline & 100 & $93.63 \pm 0.86$ & \\
\hline
\end{tabular}

Results are expressed as mean $\pm \operatorname{SEM}(n=3) ; I C_{50}=50 \%$ inhibitory concentration. BCAE: aqueous extract of Bombax ceiba

amount of collagen tissue (arrow) stained blue with Masson's trichrome stain in the portal triad [Figure 1B]. Liver section of olive oil treated animals [Figure 1A] showed normal hepatic architecture with central canal having radiating hepatocytes. Minimal amount of collagen tissue (arrow) stained blue with Masson's stain was evident in the portal triad.

The BCAE treatment $(500 \mathrm{mg} / \mathrm{kg})$ or silymarin showed significant protection against $\mathrm{CCl}_{4}$-induced hepatic damage as indicated by lesser amount of collagen tissue vascular as compared to vehicle [Figure 1B]. Treatment with $500 \mathrm{mg} / \mathrm{kg}$ dose of BCAE exhibited comparable protection [Figure 1D] to that offered by silymarin $(25 \mathrm{mg} / \mathrm{kg})$ [Figure $1 \mathrm{C}$ ].

\section{Antioxidant effect of BCAE}

Quantitative estimation of antioxidant phytochemicals

The total flavonoid content of BCAE was found to be $5.79 \mathrm{mg}$ quercetin equivalents/g of extract, while the total phenolic content was found to be $0.225 \mathrm{mg}$ tannic acid equivalent/g of extract, respectively.

\section{DPPH free radical scavenging activity}

The BCAE in concentration range of $10-100 \mu \mathrm{g} / \mathrm{mL}$ inhibited DPPH radical formation as indicated by concentrationdependent decrease in the purple color of the solution. Similar effect was obtained with ascorbic acid, the standard antioxidant, in the concentration range of $5-100 \mu \mathrm{g} / \mathrm{mL}$. The linear regression analysis of concentration vs. percent DPPH inhibition was carried out. The $\mathrm{IC}_{50}$ value of BCAE and ascorbic acid, obtained from regression analysis, were 50.21 and $3.35 \mu \mathrm{g} / \mathrm{mL}$, respectively [Table 3].

\section{DISCUSSION}

Acute toxicity study of the BCAE $(2,000 \mathrm{mg} / \mathrm{kg}$, orally) revealed that there was no toxicity of any nature or moribund stage during the observation period. This illustrates that the NOAEL of BCAE is more than $2,000 \mathrm{mg} / \mathrm{kg}$. Based on this, the $\mathrm{BCAE}$ was administered in the dose range of $200 \mathrm{mg} / \mathrm{kg}$ (one tenth of the limit test dose level). The previous studies have also used extract of Bombax ceiba in the similar dose range. ${ }^{[14]}$
In accordance with earlier reports, ${ }^{[30-32]}$ the present investigations revealed that administration of $\mathrm{CCl}_{4}$ caused a marked impairment in liver function, as indicated by significant increase in plasma levels of marker enzymes; and produced extensive histological damages to liver. $\mathrm{CCl}_{4}$ undergoes metabolism in liver to form trichloromethyl peroxyl $\left(\mathrm{CCl}_{3} \mathrm{O}_{2}\right)$ radical ${ }^{[33]}$ and several lines of evidences suggest that the free radicals oxidize the essential macromolecular structures, that is, DNA, proteins, and lipids, and eventually produce cytotoxicity. ${ }^{[34,35]}$ In addition, higher levels of lipid peroxidation are clinically evident in liver disorders ${ }^{[36]}$ and the antioxidant therapy was found to ameliorate these effects. ${ }^{[37]}$

It was observed that treatment with BCAE ameliorated the $\mathrm{CCl}_{4}$-induced impairments in the liver functions except total protein and albumin. BCAE in the dose $500 \mathrm{mg} / \mathrm{kg}$ offered moderate degree of attenuation in the elevated GOT, GPT, and TG, but with very remarkable prevention of ALP and T. The lower dose of $250 \mathrm{mg} / \mathrm{kg}$ was almost ineffective in normalizing the liver markers except for a few. BCAE also showed lesser degree of collagen fiber as compared to vehicle control [Figure 1] which suggests the preventive nature of the extract on liver tissue fibrosis. These findings confirmed that BCAE exerts moderate hepatoprotective effect. Previously the hepatoprotective effect of Bombax ceiba flowers was demonstrated in isoniazid plus rifampicin induced hepatotoxicity ${ }^{[14]}$ and supports the findings of the present study.

Phytochemical analysis of BCAE revealed the presence of the antioxidant phytochemicals flavonoids, terpenes and phenolic compounds. It has been earlier reported that the flowers and other parts of this plant contains flavonoids and sesquiterpenens, etc. ${ }^{[38,39]}$ The present study also revealed that $\mathrm{BCAE}$ has fair amount of flavonoids and phenolics.

BCAE was further tested for its antioxidant activity. The results revealed that $\mathrm{BCAE}$ has significant free radical scavenging property [Table 3] with $\mathrm{IC}_{50}$ of $50.21 \mu \mathrm{g} / \mathrm{mL}$. The antioxidant activities of the flavonoids are well 
demonstrated and they are often found effective in hepatic disorders. ${ }^{[40-42]}$ Previous studies have reported that Bombax ceiba extract possesses in vitro antioxidant activity. ${ }^{[10-12]}$ Based on this, it can be hypothesized that the observed hepatoprotection offered by BCAE may be ascribed to its antioxidant activity. Furthermore, this was supported by the observation that daily treatment with silymarin, a well proven antioxidant, showed similar effects on $\mathrm{CCl}_{4}$-induced changes in the levels of hepatic function markers and similarly prevented the $\mathrm{CCl}_{4}$-induced damage to the liver. The in vivo antioxidant activity and hepatoprotective effect of silymarin are well demonstrated in earlier studies ${ }^{[21,22]}$ and corroborate with the present findings. The observed hepatoprotective effect of BCAE was comparable to that of silymarin.

In conclusion, BCAE exhibited protective effect on $\mathrm{CCl}_{4}$-induced free radical mediated hepatotoxicity. The observed hepatoprotection by BCAE may be a consequence of its antioxidant effect due to the presence of flavonoids or other phenolic compounds in BCAE. The present investigations scientifically validate the traditional use of flowers of Bombax ceiba in hepatic disorders.

\section{Acknowledgments}

Authors are thankful to Dr. Vinay Lomesh, Shree Ram Institute of Industrial Research, New Delhi, for his help in interpretation of histological changes in liver tissues.

\section{Financial support and sponsorship}

Nil.

\section{Conflicts of interest}

There are no conflicts of interest.

\section{REFERENCES}

1. Hodgson E. A textbook of modern toxicology. 3rd ed. New Jersey: John Wiley \& Sons, Inc. Publication; 2004.

2. Ahmed NG. Hepatoprotective and anti hepatotoxic drugs from plant sources. 5th International Conference and Exhibition on Pharmaceutics \& Novel Drug Delivery Systems. Pharm Anal Acta 2015;6:1

3. Mishra LC. Scientific basis for Ayurvedic therapies. Boca Raton, New York: CRC press; 2004. p. 231-354.

4. Varier PK, Nambiar VPK, Ramankutty C. Indian medicinal plants a compendium of 500 species. Kerala: Orient Longman Publishing; 1997. p. 289-92.

5. Parrotta JA. Healing plants of peninsular India. CABI publishing; 2001.

6. Gupta AK, Sharma M, Tandon N. Reviews on Indian medicinal plants. New Delhi: Indian Council of Medical Research; 2004.

7. Saleem R, Ahmad M, Hussain SA, Qazi AM, Ahmad SI, Qazi MH, Ali M, Faizi S, Akhtar S, Husnain SN. Hypotensive, hypoglycaemic and toxicological studies on the flavonol C-glycoside shamimin from Bombax ceiba. Plant Medica 1999;65:331-4.

8. Rani P, Khullar N. Antimicrobial evaluation of some medicinal plants for their anti-enteric potential against multi-drug resistant Salmonella typhi. Phytother Res 2004;18:670-3.

9. Girija K, Udaya chandrika P, Lakshman K, Pruthvi N. Evaluation of antimicrobial activity of various bark extracts of Bombax malabaricum. Int J Res Pharm Sci 2010;1:199-204.
10. Vieira TO, Said A, Aboutabl E, Azzam M, Creczynski-Pasa TB. Antioxidant activity of methanolic extract of Bombax ceiba. Redox Rep 2009;14:41-6.

11. Gandhare B, Soni N, Dhongade HJ. In vitro antioxidant activity of Bombax ceiba. Int J Biomed Res 2010;1:31-6.

12. Jain V, Verma SK, Katewa SS, Anandjiwala S, Singh B. Free radical scavenging property of Bombax ceiba Linn. root. Res J Med Plant 2011;5:462-70.

13. You YJ, Nam NH, Kim Y, Bae KH, Ahn BZ. Antiangiogenic activity of lupeol from Bombax ceiba. Phytother Res 2003;17:341-4.

14. Ravi V, Patel SS, Verma NK, Datta D, Saleem TSM. Hepatoprotective activity of Bombax ceiba Linn against isoniazid and rifampicininduced toxicity in experimental rats. Int $J$ Appl Res Nat Prod 2010;3:19-26.

15. Wong SP, Leong LP, Koh JHW. Antioxidant activities of aqueous extracts of selected plants. Food Chemistry 2006;99:775-83.

16. Khandelwal KR. Practical pharmacognosy. 15th ed. Pune: Nirali Prakashan; 2006. p. 149.

17. Organization for Economic Cooperation and Development (OEDC), Guideline for the testing of chemicals. Revised draft guideline 423 . Document on acute oral toxicity and acute toxicity class method; 2001. Available from: www.oecd.org.

18. Sengottuvelu S, Duraisami S, Nandhakumar J, Duraisami R, Vasudevan M. Hepatoprotective activity of Camellia sinensis and its possible mechanism of action. Iranian J Pharmacol Ther 2008;7:9-14.

19. Ye X, Feng Y, Tong Y, Ng KM, Tsao S, Lau GK, Sze C, Zhang Y, Tang J, Shen J, Kobayashi S. Hepatoprotective effects of Coptidis rhizoma aqueous extract on carbon tetrachloride-induced acute liver hepatotoxicity in rats. J Ethnopharmacol 2009;124:130-6.

20. Sorg DA, Buckner B. A simple method of obtaining venous blood from small laboratory animals. Proc Soc Exp Biol Med 1964;115:1131-2.

21. Bindoli A, Cavallini L, Siliprandi N. Inhibitory action of silymarin on lipid peroxide formation in rat liver mitochondria and microsomes. Biochem Pharmacol 1977;26:2405-9.

22. Lettéron P, Labbe G, Degott C, Berson A, Fromenty B, Delaforge M, Larrey D, Pessayre D. Mechanism for the protective effects of silymarin against carbon tetrachloride-induced lipid peroxidation and hepatotoxicity in mice. Evidence that silymarin acts both as an inhibitor of metabolic activation and as a chain-breaking antioxidant. Biochem Pharmacol 1990;39:2027-34.

23. Reitman S, Frankel S. A colorimetric method for determination of serum glutamic oxalacetic and glutamic pyruvic transaminases. Am J Clin Pathol 1957;28:56-63.

24. Kind PR, King EJ. Estimation of plasma phosphatase by determination of hydrolysed phenol with amino-antipyrine. $J$ Clin Pathol 1954;7:322-6.

25. Jendrassik L, Grof P. Simplified photometric methods for the determination of the blood bilirubin. Biochem J 1938;297:81-9.

26. Flack CP, Woollen JW. Prevention of interference by dextran with biuret-type assay of serum proteins. Clin Chem 1984;30:559-61.

27. Singleton VL, Rossi Jr. JA. Colorimetry of total phenolics with phosphomolybdic- phosphotungstic acid reagents. Am J Enol Viticult 1965;16:144-58.

28. Marinova D, Ribarova F, Atanasova M. Total phenolics and flavonoids in bulgarian fruits and vegetables. J Univ Chem Tech Metall 2005;40:255-60.

29. Brand-Williams W, Cuvelier ME, Berset C. Use of a free radical method to evaluate antioxidant activity. Lebensm-Wiss u.-Technol 1995;28:25-30.

30. Recknagel RO. Carbon tetrachloride hepatotoxicity. Pharmacol Rev 1967;19:145-208.

31. Ploa GL, Hewitt WR. Detection and evaluation of chemically induced liver injury. In: Hayes W, editor. Principles and methods of toxicology. 2nd ed. New York: Raven Press; 1989. p. 399-628.

32. Ilavarasan R, Vasudevan M, Anbazhagan S, Venkataraman S. Antioxidant activity of Thespesia populnea bark extracts against carbon tetrachloride-induced liver injury in rats. J Ethnopharmacol 2003;87:227-30.

33. Tappel AL. Lipid peroxidation damage to cell components. Fed Proc 
$1973 ; 32: 1870-4$.

34. Ames BN, Shigenaga MK, Hagen TM. Oxidants, antioxidants, and the degenerative diseases of aging. Proc Natl Acad Sci U S A 1993;90:7915-22.

35. McCord JM. Human disease, free radicals, and the oxidant/antioxidant balance. Clin Biochem 1993;26:351-7.

36. Tasaduq SA, Singh K, Sethi S, Sharma SC, Bedi KL, Singh J, Jaqqi BS, Johri RK. Hepatocurative and antioxidant profile of HP-1, a polyherbal phytomedicine. Hum Exp Toxicol 2003;22:639-45.

37. Muriel P, Moreno MG. Effects of silymarin and vitamins E and C on liver damage induced by prolonged biliary obstruction in the rat. Basic Clin Pharmacol Toxicol 2004;94:99-104.

38. Faizi S, Ali M. Shamimin: a new flavonol C-glycoside from leaves of Bombax ceiba. Planta Med 1999;65:383-5.
39. Shahat AA, Hassan RA, Nazif MN, Van Miert S, Pieters L, Hammuda FM, Vlietinck AJ. Isolation of mangiferin from Bombax malabaricum and structure revision of shamimin. Planta Med 2003;69:1068-70.

40. Pavanato A, Tuñón MJ, Sánchez-Campos S, Marroni CA, Llesuy S, González-Gallego J, Marroni N. Effects of quercetin on liver damage in rats with carbon tetrachloride-induced cirrhosis. Dig Dis Sci 2003;48:824-9.

41. Wu Y, Wang F, Zheng Q, Lu L, Yao H, Zhou C, Wu X, Zhao Y. Hepatoprotective effect of total flavonoids from Laggera alata against carbon tetrachloride-induced injury in primary cultured neonatal rat hepatocytes and in rats with hepatic damage. $J$ Biomed Sci 2006;13:569-78.

42. Chen YT, Zheng RL, Jia ZJ, Ju Y. Flavonoids as superoxide scavengers and antioxidants. Free Rad Biol Med 1990;9:19-21. 